\title{
Desenvolvimento rural no Cerrado, desenvolvimento e envolvimento das famílias agroextrativistas
}

\author{
Rural development in the Cerrado, development and involvement in agroextractivism families
}

\author{
Sued Wilma Caldas Melo ${ }^{1}$
}

\begin{abstract}
Resumo
O bioma Cerrado destaca-se por prestar serviços ambientais importantes para o equilíbrio ecológico do planeta e por abrigar um sem-número de comunidades tradicionais que têm na utilização dos seus recursos fonte de sobrevivência física e cultural. Entretanto, encontra-se ameaçado pelo modelo de desenvolvimento hegemônico que, fomentando a expansão da produção de commodities para exportação em sistemas de grandes monoculturas, devasta a sua biodiversidade e dificulta as condições de existência das comunidades que ali vivem e trabalham. O desenvolvimento rural nas áreas de abrangência do Cerrado brasileiro deve atuar na busca por inclusão social e redução da pobreza e contemplar questões relativas à preservação e sustentabilidade ambiental. O objetivo deste artigo foi analisar o desenvolvimento rural no bioma Cerrado tomando como abordagem central o uso sustentável de sua biodiversidade e as estratégias de produção e reprodução social das famílias agroextrativistas. O instrumento metodológico articulou as novas abordagens do desenvolvimento rural com discussões sobre agroextrativismo e pesquisa de campo realizada com famílias do Projeto de Assentamento Vale da Esperança. Os resultados apontam o agroextrativismo como uma forma alternativa de uso dos recursos do Cerrado com potencialidades ambientais, sociais e econômicas.
\end{abstract}

Palavras-chave: Desenvolvimento rural. Bioma Cerrado. Agroextrativismo.

\begin{abstract}
The Cerrado biome stands for making important environmental services for the ecological equilibrium of our planet, and for harboring traditional communities who get their physical and cultural survival. However, this biome is being menaced by the hegemonic development model. This model, by fomenting the expansion of the production of commodities for exportation and big monoculture-systems, ravages the biodiversity and derail the existence conditions of the communities which live and work in it. Rural development in the Cerrado ask for social inclusion and poverty reduction, and include issues related to environmental preservation and sustainability. The purpose of this article is to discuss rural development taking as a central approach the sustainable use of its biodiversity and the strategies of production and social reproduction of the agroextractivist families. The methodology articulate modern rural development approach with discussions about extraction, this analysis was enhanced with information from field research performed on Projeto de Assentamento Vale da Esperança. The results point agroextrativism as a rural development strategy which can contribute to increase and diversify the income sources, to maintain the cultural heritage and for preservation of the remaining areas of the biome.
\end{abstract}

Keywords: Rural development. Cerrado Biome. Agroextractivism.

1 Doutoranda do Programa de Pós-graduação em Desenvolvimento Sociedade e Cooperação Internacional - UnB.

E-mail: suedcaldas@gmail.com

Guaju, Matinhos, v.3, n.1, p. 111-131, jan./jun. 2017 


\section{Introdução}

O termo "Cerrado" é utilizado para indicar o tipo de vegetação que predomina na porção central do Brasil. Trata-se de uma região natural exclusivamente brasileira (exceto por pequena área no nordeste da Bolívia) marcada pela heterogeneidade espacial e elevada riqueza biológica. Além de abrigar aproximadamente um terço da fauna e da flora brasileira e cerca de $5 \%$ da biota planetária, contempla formações florestais (Mata Ciliar, Mata de Galeria, Mata Seca e Cerradão), savânicas (Cerrado sentido restrito, Parque Cerrado, Palmeiral e Vereda) e campestres (Campo sujo, Campo Rupestre e Campo limpo), formando um verdadeiro mosaico de paisagens naturais (DIAS, 1996).

O Cerrado é o segundo maior bioma brasileiro em área. Sua extensão territorial é de aproximadamente 2 milhões de $\mathrm{km}^{2}$, o que representa quase $25 \%$ da área total do Brasil. Esta extensão corresponde apenas à área nuclear, se considerarmos as áreas de transição entre o Cerrado e os outros biomas que ele estabelece contato - Floresta Amazônica, Mata Atlântica, Caatinga e Pantanal e ainda as ilhas de Cerrado na Amazônia - sua área total de ocorrência atinge aproximadamente 3 milhões de $\mathrm{km}^{2}$, retratando quase 37\% da superfície brasileira (DIAS, 1996).

O bioma Cerrado desempenha papel relevante na manutenção dos recursos hídricos brasileiros. Abriga sob o seu domínio um dos maiores reservatórios de águas subterrâneas, o aquífero Guarani e também capta e distribui as águas que vão alimentar a maior parte das bacias hidrográficas brasileiras (São Francisco, Tocantins, Paraná, Amazonas, Paraguai e Parnaíba) e ainda, trechos de bacias sul-americanas. Tal função se deve, principalmente, às características específicas do relevo e dos solos de suas chapadas que permitem que elas funcionem como espécie de esponja que absorve água e alimenta os lençóis freáticos (SILVA, 2009a).

Significativa identidade sociocultural é encontrada nos espaços que compõem o Cerrado. O bioma representa espaço de vida e de trabalho para inúmeras comunidades tradicionais, indígenas, quilombolas de origem camponesa e de base familiar. Estas são detentoras de um legítimo patrimônio cultural, construíram uma outra racionalidade de convivência, produção e reprodução social mais íntima e harmônica com os ecossistemas do bioma, em geral mais compatíveis com os princípios da sustentabilidade. Não obstante as características individuais de cada uma, para este trabalho, serão todas denominadas como agricultores familiares (SILVA, 2009a). 
A despeito de sua elevada biodiversidade e significativa identidade sociocultural, o Cerrado é um dos biomas mais ameaçados do planeta, figura entre os 25 hotsposts mundiais (MYERS et al., 2000) e representa o bioma brasileiro que mais sofreu alterações antrópicas. Segundo estatísticas divulgadas pelo Ministério do Meio Ambiente (MMA), em 2010, aproximadamente metade da sua área original já havia sido transformada em pastagens plantadas, culturas anuais e outros tipos de uso (BRASIL, 2011). Estimativas indicam que somente cerca de $20 \%$ do bioma estejam realmente intactos. Apenas 8,2\% de sua área encontram-se protegidos sob a forma de unidades de conservação, dentre os quais, menos de $3 \%$ representam unidades de conservação integral. Pelo menos $20 \%$ de suas espécies endêmicas e ameaçadas permanecem fora dos parques e reservas existentes. Enquanto137 animais, 132 plantas do bioma já estão na lista nacional de espécies ameaçadas de extinção (KLINK; MACHADO, 2005).

Grande parte deste quadro de devastação está diretamente relacionada a forma de ocupação que vem sendo priorizada na região Centro-Oeste (região de predomínio do bioma Cerrado) desde o processo de modernização agrícola iniciado em meados dos anos 1960 (SILVA, 2009a). Tratase de um modelo agropecuário baseado na criação extensiva de gado e em sistemas de monoculturas destinadas a plantação de commodities para exportação. Por se tratar de uma expansão praticamente desenfreada que cresce a cada ano, este modelo agropecuário se expande também por extratos de área de vegetação nativa, o que devasta a biodiversidade e dificulta as condições de existência das comunidades de agricultores familiares que têm nos recursos naturais do bioma importante fonte de produção e reprodução social.

Entretanto, o que pode ser encarado como a questão central não é o modelo agropecuário, mas sua expansão desordenada e a visão muitas vezes reducionista e limitada com que o bioma Cerrado vem sendo tratado pelos gestores públicos e pela sociedade em geral. Ao invés de potencializarem as inúmeras possibilidades de geração de emprego e renda que podem ser alcançadas a partir do uso sustentável da biodiversidade, as áreas cobertas pelo bioma são tidas apenas como substrato para a expansão monocultora, como se a única utilidade e valor fosse a geração de divisas para o país. Sendo que predomina ainda uma espécie de rejeição quando comparado a outros biomas brasileiros, os maiores esforços de conservação ambiental, por exemplo, têm sido voltados, prioritariamente, para a Amazônia e Mata Atlântica, em detrimento dos recursos naturais do Cerrado (SILVA, 2009a).

É com base neste contexto que existe a necessidade de se criar, fomentar e valorizar alternativas econômicas mais sustentáveis e includentes para a região do Cerrado que, além do 
enfoque ambiental, estejam inseridas na abordagem do desenvolvimento rural. Nesta perspectiva, preconiza-se que as iniciativas e estratégias de desenvolvimento rural devem ampliar os objetivos do desenvolvimento para abranger não apenas crescimento econômico, mas também aspectos de cunho social que promovam mudanças positivas nas vidas das comunidades rurais, como redução das desigualdades, mitigação da pobreza e bem-estar social (ABRAMOVAY, 2012).

O objetivo deste trabalho é analisar o desenvolvimento rural no bioma Cerrado tomando como abordagem central o uso sustentável de sua biodiversidade e as estratégias de produção e reprodução social das comunidades agroextrativistas. Para tanto, os instrumentos metodológicos articularam revisão de literatura a respeito do desenvolvimento rural e do agroextrativismo com informações advindas de pesquisa de campo realizada entre junho e agosto de 2012 no Projeto de Assentamento Vale da Esperança. Para coleta dos dados foram realizadas entrevistas semiestruturadas e em profundidade com nove famílias agroextrativistas do assentamento.

O Vale da Esperança foi criado pelo Instituto Nacional de Colonização e Reforma Agrária (INCRA), em 15 de julho de 1996, através da desapropriação de 5.614,4 ha da antiga fazenda Vale da Esperança, localizada a 76 Km da cidade de Formosa GO. Em 2012, ano de realização da pesquisa, o assentamento completou 16 anos e contava com 176 famílias assentadas, das quais vinte e duas eram agroextrativistas. A escolha do Vale da Esperança para a realização do estudo deveu-se aos aspectos geográficos (localização no estado de Goiás, unidade da federação que possui mais de $95 \%$ do seu território coberto pelo Cerrado e que compôs as áreas de expansão da chamada fronteira agrícola) e à experiência local com o extrativismo dos frutos do Cerrado, incluindo a atuação da Cooperativa Mista do Vale da Esperança (COOPERVAL).

Este trabalho aponta as potencialidades da agricultura familiar e destaca a sua importância enquanto ator social que deve estar à frente de qualquer proposta de desenvolvimento quando o objetivo for erradicar a pobreza, reduzir as desigualdades e respeitar o meio ambiente; abordagem que pretende romper com a visão reducionista de desenvolvimento rural produtivista e industrial. Além da presente introdução, o artigo está estruturado em mais cinco seções. A segunda discute as concepções do desenvolvimento rural, suas prerrogativas e principais abordagens. A terceira apresenta o Cerrado, suas especificidades, analisando o processo de desenvolvimento rural no bioma. A quarta seção enfoca os agricultores familiares do Cerrado, relacionando seus modos de vida e estratégias de reprodução social com o desenvolvimento almejado para o Cerrado. Na quinta, a análise recai sobre o agroextrativismo e suas potencialidades para o desenvolvimento rural. E por fim, na sexta seção são apresentas as conclusões do artigo. 


\section{Desenvolvimento Rural}

Ao longo dos anos, a noção de desenvolvimento rural tem apresentado significados e compreensões distintas. Não se trata de um conceito estático, mas sim de um conjunto de ideias que se altera ao longo do tempo, influenciado por diversas conjunturas, principalmente, pelos novos condicionantes que o desenvolvimento mais geral da economia e da vida social impõe às famílias e às atividades rurais. Na época da modernização da agricultura, por exemplo, a ideia de desenvolvimento rural era restrita ao desenvolvimento agrícola e incluía necessariamente a intensificação tecnológica e o uso crescente de insumos tidos como modernos. Desenvolvimento era entendido como sinônimo de progresso e crescimento econômico que seriam alcançados através da industrialização, urbanização e obtenção de indicadores econômicos positivos (NAVARRO, 2001).

Neste período, a noção de desenvolvimento era fortemente associada à indústria e à urbanização, o que desencadeou um forte viés urbano ao processo de desenvolvimento. As sociedades predominantemente rurais e com baixo grau de industrialização eram tidas como atrasadas, e o rural, em oposição ao urbano, foi relegado a um papel secundário e residual, um lugar sem perspectivas de crescimento, que deveria inevitavelmente se desenvolver. Sob pena de desaparecimento e inviabilidade das áreas rurais, os esforços voltaram para a construção de uma estrutura empresarial para o setor agropecuário que contemplasse um projeto de industrialização da agricultura (MORAES et al., 2008).

Frente aos novos cenários marcados por mudanças (rápidas, profundas e inéditas) de âmbito social e econômico que modificaram drasticamente estruturas, modelos e formas de organização da sociedade, a noção de desenvolvimento como sinônimo de crescimento econômico tornou-se insatisfatória e insuficiente. Inquietações que marcam o início dos debates que vislumbram a construção de uma nova concepção do desenvolvimento rural, direcionada para a tentativa de superar a pobreza e as desigualdades que permeiam os espaços rurais e para a promoção de bem-estar social, melhoria das condições de vida, garantia direitos e liberdades individuais e respeito ao meio ambiente (SAUER, 2008).

O debate recente sobre o desenvolvimento rural no Brasil é marcado pelo que Delgado (2010) chama de confluência perversa entre dois projetos distintos e excludentes de desenvolvimento rural: o projeto neoliberal e o projeto democratizante. O projeto neoliberal corresponde à produção de commodities para exportação em sistemas extensivos de monoculturas. 
É o projeto que defende o modelo produtivista de desenvolvimento rural, que teve origem com a revolução verde e que ainda hoje constitui a proposta dominante de desenvolvimento. Em sua essência, dá continuidade ao modelo de modernização da agricultura concentrador e excludente. Esta forma de produção vem sendo fortalecida em virtude de seu peso político diante do Estado, concordância por uma parte da sociedade e também graças à sua projeção e exposição favorável na mídia. Fazendo com que seja vista sob um caráter de "imprescindibilidade" (DELGADO, 2010).

Entretanto, a análise histórica demonstra que essa opção política por fomentar a grande propriedade agropecuária trouxe consequências desastrosas no que diz respeito à concentração fundiária e à distribuição de riqueza, implicando em desigualdades sociais que geram fome, pobreza e exclusão social. A predominância de grandes propriedades aumenta o desemprego rural e acarreta no êxodo de sua população para as periferias urbanas. Isto, além de implicar em novos problemas urbanos, conduz à perda do dinamismo do espaço rural, pois com a saída em número expressivo de seus habitantes, este espaço perde direta e imediatamente sua vitalidade social. Com isso, as famílias que ainda persistem no local têm suas condições de reprodução social dificultadas ou, até mesmo, inviabilizadas (WANDERLEY, 2000a).

É neste cenário que ganham força as abordagens do desenvolvimento rural voltadas para o fortalecimento e incentivo à agricultura familiar. Opção que Delgado (2010) denomina de projeto democratizante, e escolhida para enfatizar o processo de democratização da sociedade. Este projeto teve como propostas iniciais a reforma agrária, a ampliação do mercado interno e a luta contra a exclusão social e a pobreza e como protagonistas as identidades sociais estabelecidas na década de 1990 "sem terra", "assentados" e "agricultores familiares". Atualmente, incorpora novos atores e propostas como, por exemplo, o reconhecimento dos direitos sociais das populações rurais, a democratização do acesso às políticas públicas, a segurança alimentar e nutricional da população brasileira (DELGADO, 2010).

De encontro ao dualismo apresentado por Delgado (2010), Schneider (2010) elucida que a discussão sobre desenvolvimento rural no Brasil está impregnada de um sentido político e ideológico que se alimenta e fortalece à medida que ganha destaque e legitimidade a polarização entre os defensores da agricultura familiar e da produção empresarial de commodities em sistemas de monocultivos. Neste sentido, o autor adverte que, quando se trata de analisar o desenvolvimento rural, é imperioso saber a quem este desenvolvimento está endereçado, o que ele apresenta e quem dele se beneficia. 
Deste modo, é difícil definir o que são, substancialmente, estudos sobre desenvolvimento rural. Mesmo considerando apenas a concepção de desenvolvimento rural centrada na agricultura familiar (enfoque entendido neste trabalho como o mais adequado), é possível identificar várias abordagens teóricas, com distintas perspectivas analíticas e interpretativas. Outro desafio é que estes enfoques raramente convergem em relação às perspectivas e tendências para o meio rural e menos ainda no que se refere às estratégias de intervenção a ser seguidas. Sente-se falta também de definições claras em relação a metodologias, corpus de conceitos e escopo do desenvolvimento rural, e, até mesmo de experiências empíricas que possam servir de referência e serem replicadas (SCHNEIDER, 2010).

Sem a intenção de esgotar o tema, Schneider (2010) apresenta quatro abordagens teóricas que considera as principais nos debates recentes sobre o desenvolvimento rural no Brasil: 1) Instituições, inovação e sustentabilidade; 2) O novo rural brasileiro; 3) A "força da tradição" e os limites históricos e sociais ao desenvolvimento rural e 4) O enfoque agroalimentar. O Quadro 01 resume os fundamentos e as características de cada uma delas.

\section{QUADRO 01 - PRINCIPAIS ABORDAGENS TEÓRICAS DO DESENVOLVIMENTO RURAL}

\begin{tabular}{|c|c|}
\hline $\begin{array}{c}\text { Instituições, } \\
\text { inovação e } \\
\text { sustentabilidade }\end{array}$ & $\begin{array}{l}\text { Abordagem articulada em torno de uma matriz multidisciplinar em que se destacam a } \\
\text { economia, a ecologia e a sociologia econômica. Enfoca a valorização da agricultura familiar e } \\
\text { o reconhecimento de seu potencial dinamizador das economias locais. Argumenta que a } \\
\text { capacidade empreendedora e inovadora dos agricultores familiares é a responsável pela } \\
\text { diversificação social e produtiva dos territórios rurais em que vivem. Seus trabalhos dialogam } \\
\text { com as discussões sobre as dinâmicas territoriais do desenvolvimento do espaço rural e são os } \\
\text { grandes influenciadores do surgimento da noção de desenvolvimento territorial no Brasil. }\end{array}$ \\
\hline $\begin{array}{c}\text { O novo rural } \\
\text { brasileiro }\end{array}$ & $\begin{array}{l}\text { Perspectiva iniciada com o Projeto Rurbano o qual demonstrou que o meio rural já não pode } \\
\text { ser considerado exclusivamente agrícola, representando um novo Brasil rural. Neste, o rural se } \\
\text { desconecta da agricultura e aumenta a quantidade de pessoas ocupadas em atividades não } \\
\text { agrícolas. São famílias pluriativas que combinam atividades agrícolas e não-agrícolas e } \\
\text { promovem a integração intersetorial (agricultura com comércio e serviços) e interespacial (rural } \\
\text { com urbano). O projeto identificou três grupos de atividades no rural brasileiro: uma } \\
\text { agropecuária moderna baseada em commodities e intimamente ligada as agroindústrias; um } \\
\text { conjunto de atividades não agrícolas ligadas à moradia, ao lazer e a várias atividades industriais } \\
\text { e de prestação de serviços e, por fim, um conjunto de novas atividades agropecuárias, } \\
\text { impulsionadas por nichos de mercado. E ainda a existência de uma ampla parcela da população } \\
\text { identificada como "sem-sem", sem terra, emprego, educação, saúde e renda, e sem organização } \\
\text { social. }\end{array}$ \\
\hline $\begin{array}{l}\text { A "força da } \\
\text { tradição" e os } \\
\text { limites históricos e } \\
\text { sociais ao } \\
\text { desenvolvimento } \\
\text { rural }\end{array}$ & $\begin{array}{l}\text { As discussões abordam os mecanismos de dominação social e cultural construídos } \\
\text { historicamente por elites locais para legitimar seu poder e manter os seus privilégios. O } \\
\text { clientelismo, a tradição política de tipo tradicional e patriarcal, entre outros, representam limites } \\
\text { e dificuldades que remetem à própria formação do tecido social brasileiro e são os principais } \\
\text { responsáveis pela ausência de transformações estruturais e de mudanças de natureza } \\
\text { sociocultural. Estes limites históricos do desenvolvimento apontam para a necessidade da } \\
\text { promoção de processos radicais de democratização, a fim de libertar os indivíduos e grupos } \\
\text { sociais da tutela e controle exercido pelas elites e pelos mediadores (agentes da Igreja, do } \\
\text { Estado, dos partidos políticos, dos movimentos sociais). Só assim será possível ampliar as }\end{array}$ \\
\hline
\end{tabular}




\begin{tabular}{|c|l|}
\hline & $\begin{array}{l}\text { condições e possibilidades do desenvolvimento rural e promover alteração das condições de } \\
\text { vida das populações em situação de vulnerabilidade. }\end{array}$ \\
\hline $\begin{array}{c}\text { O enfoque } \\
\text { agroalimentar }\end{array}$ & $\begin{array}{l}\text { Abordagem analisa as formas de integração dos pequenos produtores (embora não apenas } \\
\text { destes) nas cadeias agroindustriais ou agroalimentares, revelando uma preocupação } \\
\text { consequente com os aspectos sociais deste processo. Ou seja, busca entender em que condções } \\
\text { os pequenos produtores e suas organizações podem fazer frente aos desafios colocados pela } \\
\text { forma atual como o capitalismo opera na agricultura e na produção de alimentos. }\end{array}$ \\
\hline
\end{tabular}

FONTE: Elaborado a partir de Schneider (2010)

De modo simplificado, este trabalho entende como desenvolvimento rural um processo complexo e necessariamente multidimensional, que envolve uma diversidade de atividades, um amplo espectro de relações sociais e múltiplos atores, mas que tem como protagonista a agricultura familiar. Seus objetivos são mais includentes e democráticos, consideram a redução das desigualdades sociais, mitigação da pobreza e geração de melhores condições de vida para as populações rurais. E suas práticas e estratégias necessariamente consideram as potencialidades dos ecossistemas locais e a preservação das paisagens, florestas e do meio ambiente como um todo.

Acredita-se que a noção de território constitua a unidade de referência mais adequada para se estudar e analisar os processos amplos do desenvolvimento rural. Este enfoque territorial supera a análise setorial das atividades econômicas (agricultura, indústria, comércio, serviços, etc.) e a dicotomia espacial entre o rural versus urbano ou o campo versus cidade (SCHNEIDER, 2010). Além de considerar o alargamento da abrangência espacial, ocupacional e setorial do rural, visto como espaço que não contempla apenas o aspecto produtivo (que por sua vez não se restringe à agricultura), mas inclui múltiplas atividades como lazer, moradia e até mesmo a prestação de serviços ambientais.

\section{Desenvolvimento Rural no Cerrado}

O bioma Cerrado possui inestimável valor intrínseco. Sua importância não se restringe aos aspectos ambientais, penetra o nível social e ultrapassa as fronteiras dos espaços, atingindo a sociedade como um todo. Reconhecer tais potencialidades naturais e sociais do Cerrado, bem como admitir as consequências perversas que o modelo agropecuário hegemônico causou, tanto para as comunidades que habitam o bioma, quanto para o meio ambiente, implica em desafios 
ainda maiores quando se trata de pensar as diretrizes e objetivos do desenvolvimento rural no Cerrado.

Atualmente, o desenvolvimento rural no bioma é marcado pelo forte embate entre desenvolvimento econômico e sustentabilidade social e ambiental. Apesar de toda relevância ambiental e expressiva diversidade sociocultural, o Cerrado representa um dos biomas mais ameaçados pela pressão antrópica (MYERS et al., 2000), e constitui território em que o modelo agropecuário industrial e produtivista se instalou mais intensamente, deixando implicações perversas.

A despeito da predominância produtivista, a aptidão agropecuária não representa a única vocação e muito menos a única possibilidade que o Cerrado oferece ao desenvolvimento rural. De acordo com Abramovay (1999), as atividades agrícolas devem continuar ocorrendo e sendo apoiadas, mas é inevitável que os seus fundamentos sejam repensados. Em detrimento da ocupação e devastação de novas áreas, deve-se primar pelo aumento de produção alcançado através do melhor aproveitamento das áreas já abertas, com aumento da produtividade e com a adoção de métodos que não exijam a ampliação dos insumos químicos; bem como pela recuperação das áreas de pastagem degradadas e do patrimônio produtivo já instalado (ABRAMOVAY, 1999).

Neste sentido, Sawyer e Lobo (2008) argumentam que no Cerrado há espaço suficiente para produção comercial exportadora, sociodiversidade e conservação das funções ecossistêmicas. Para isso, o ideal seria conter a produção monocultora nos aproximadamente 980 mil quilômetros quadrados que não possuem mais cobertura vegetal original e destinar outros 200 mil quilômetros quadrados $(10 \%)$ para unidades de conservação, conforme recomendado pela meta internacional da Conversão de Diversidade Biológica. Assim, haveria cerca de 840 mil quilômetros quadrados para policultura e extrativismo, a serem desenvolvidos pela agricultura familiar; formas de uso da terra mais compatível com a manutenção de funções ecossistêmicas de água, biodiversidade e clima (SAWYER; LOBO, 2008).

Dada a relevância social, ambiental e econômica do Cerrado, caso não sejam tomadas medidas mais adequadas e condizentes com os conceitos de sustentabilidade ambiental e valorização social, as implicações negativas do modelo produtivista de desenvolvimento podem se tornar ainda mais devastadoras e completamente irremediáveis (SAWYER; LOBO, 2008). As abordagens do desenvolvimento rural nas áreas de Cerrado devem passar pela construção de uma visão integrada que estabeleça sinergismos positivos entre população, meio ambiente e desenvolvimento, evitando a degradação tanto do ambiente natural, quanto dos seres humanos que 
habitam o bioma. Os ecossistemas e a biodiversidade não podem ser restringidos como um limite a ser superado pelas exigências da produção agropecuária, mas devem, antes de tudo, ser vistos como oportunidades, como o maior trunfo e valor para o desenvolvimento (SAWYER, 2000).

Deste modo, qualquer proposta que objetive o desenvolvimento rural neste bioma deve estimular formas sustentáveis de ocupação e exploração da terra e desestimular a expansão da fronteira agrícola (cuja instalação supõe a drástica redução da biodiversidade). Para isto, não há uma alternativa única e sequer apenas um caminho a ser percorrido. A diversidade não representa apenas uma das características fundamentais do espaço rural do Cerrado, é também o seu maior patrimônio, devendo ser potencializada como vetor do desenvolvimento. Faz-se, pois, imprescindível aceitar as múltiplas atividades, trajetórias e estratégias possíveis e existentes.

A partir da premissa que os potenciais de desenvolvimento, existentes nos espaços rurais cobertos pelo Cerrado, vão muito além daqueles contidos estritamente no crescimento da agropecuária industrial e altamente tecnificada e que é completamente possível o empreendimento de estratégias de ocupação e uso do bioma que combinem preservação ambiental com uma exploração econômica racional de seus recursos naturais, acredita-se que devem ser os agricultores familiares os atores centrais e os protagonistas deste processo.

A agricultura familiar constitui uma forma promissora de lidar com o desemprego, com a pobreza e com as desigualdades. Além de se basearem na internalização da natureza e deterem uma lógica menos mercantil de uso da terra, as famílias portam uma racionalidade fundamentada na reprodução social, valorizam a ajuda mútua, a autonomia e a reciprocidade. Seus modos de produção pautados na quantidade e na qualidade do trabalho familiar abastecem o mercado interno de alimentos, apresentam um caráter essencialmente distributivo e ainda possuem potencial dinamizador das economias locais (WANDERLEY, 1996). A valorização, o fomento e o estímulo aos modos de vida dos agricultores familiares representam, portanto, umas das possibilidades do desenvolvimento rural no bioma Cerrado, pois, como discutido na próxima seção, são eles os verdadeiros guardiões do bioma.

\section{Agricultura familiar, envolvimento e desenvolvimento no Cerrado}

Nos espaços rurais do Cerrado, coexistem uma variedade de ecossistemas, populações, culturas, sistemas produtivos, formas de organização social e política. Esta diversidade 
corresponde a um sem-número de comunidades tradicionais, indígenas, quilombolas, dentre outras que a despeito das precárias condições de conservação ambiental, permanecem habitando o bioma e têm nele espaço de vida e trabalho. Segundo informações do MMA, existem cerca de 93 territórios indígenas concentrados principalmente no estado do Maranhão e Mato Grosso, e distribuídos em aproximadamente 11 milhões de hectares cobertos pelo Cerrado. Há ainda centenas de comunidades remanescentes de quilombos, como o Kalunga no nordeste de Goiás, e o Mata Cavalo, no município de Nossa Senhora do Livramento no MT (BRASIL, 2007).

Além destas, existem várias comunidades de origem camponesa que possuem particularidades locais e identidades distintas, bem como suas respectivas denominações, em geral, relacionadas aos ecossistemas que habitam. Trata-se dos geraizeiros (especialmente no Norte de Minas); retireiros (áreas alagadas do Araguaia MT); pantaneiros (MT e MS); quebradeiras de coco e babaçueiras (zona de transição entre o Cerrado e a Amazônia); barranqueiros e vazanteiros das beiras e ilhas (São Francisco, em MG); entre outras denominações mais gerais como, varjeiros e ribeirinhos (SILVA, 2009a).

Além da existência dessas comunidades consideradas tradicionais, o Cerrado abriga também uma variedade de outras comunidades que, de modo geral, podem ser denominadas, por nomenclatura mais recente, como agricultores familiares. Entre estas encontram-se assentados de reforma agrária; pequenos produtores rurais e agricultores de base familiar e ainda famílias que viveram e trabalharam no campo, mas que por diversos motivos passaram a residir nas cidades e que estão retomando suas origens (SAWYER, 2000).

Essas comunidades tradicionais, indígenas, quilombolas, de origem camponesa e/ou de base familiar, a despeito de suas singularidades, são denominadas neste trabalho como agricultores familiares. Associação possível em virtude de partilharem dos mesmos princípios e possuírem características comuns, como a racionalidade não estritamente mercantil de utilização dos recursos e perfil de organização e reprodução social ancorados na lógica camponesa.

Um dos principais argumentos que apontam os agricultores familiares como os atores protagonistas do desenvolvimento rural no Cerrado diz respeito à lógica totalmente oposta com que encaram os ecossistemas do bioma quando comparada aos grandes proprietários fundiários. Enquanto os agricultores familiares são ao mesmo tempo usuários e cuidadores dos recursos do bioma, na dinâmica dos proprietários de grandes terras o Cerrado é visto como uma mercadoria, como um negócio (SILVA, 2009b). Em outras palavras, para os proprietários de grandes porções fundiárias, a posse da terra está associada, quase sempre, a objetivos econômicos, que incluem 
desde os investimentos produtivos até a mera especulação fundiária. Como raramente o proprietário e sua família habitam estas áreas, não há envolvimento com a vida social local, caracterizando uma dissociação entre posse da terra e função residencial, o que, por sua vez, configura uma forma urbana de apropriação do meio rural que pode ter ou não um caráter produtivo (WANDERLEY, 2000b).

Esta lógica continua imperando mesmo nos casos em que a grande propriedade fundiária é destinada para a produção agropecuária, pois, ainda assim, continua predominando a dinâmica mercantil em que o ambiente ocupa o lugar de suporte de atividades puramente econômicas. A produção de commodities em sistemas de grandes monoculturas representa um modo de produção marcadamente exógeno, determinado por um modo de vida construído fora do lugar de produção. Com isso, um lugar repleto de histórias e significações é transformado em não-lugar e paisagens heterogêneas, de elevada riqueza biológica se tornam paisagens homogêneas e industriais. $\mathrm{O}$ espaço vivido se torna espaço de exploração, suporte físico da produção de mercadorias que alimenta o circuito da economia global. O que rege o lugar não é mais a identidade local, forjada na convivência com os ecossistemas e sim o mercado agroalimentar global e as corporações transnacionais que comandam as cadeias produtivas (SILVA, 2005).

É neste sentido que, na perspectiva de Silva (2009b), o Cerrado pede um outro envolvimento, pois neste bioma é possível observar todas as consequências perversas do modelo hegemônico que se convencionou chamar de desenvolvimento. O que Silva (2009b) denominou de envolvimento é justamente para contrapor à dominação das monoculturas, que a serviço do desenvolvimento, segue estritamente o caráter essencial do vocábulo, isto é, des-envolve, não cria vínculos. Segundo o autor:

É rompendo com o envolvimento do lugar, dos povos com seu ambiente, que se faz o desenvolvimento no Cerrado. É rompendo com a sociobiodiversidade que se constrói o negócio da monocultura-commodity. É expropriando as comunidades locais e implantando estruturas transnacionais que o lugar se torna mercadoria para o circuito global. É tirando os cerrados tortos das chapadas e substituindo-os por paisagens uniformes-industriais que a caixa d'água é desmontada e os rios, córregos e nascentes deixam de alimentar as famílias e as bacias hidrográficas estratégicas para o país (SILVA, 2009b, p 106).

Os agricultores familiares, por outro lado, realmente vivem e fazem parte dos ecossistemas que compõem o bioma. Para eles o maior valor do Cerrado é antes de tudo o valor da vida de todos os seres e elementos que o constituem, que nele habitam e que dele dependem: os homens, as 
mulheres, os bichos, as plantas, a terra, as águas, os minerais e não apenas um campo de investimento ou uma reserva de valor. O Cerrado para seus povos é ao mesmo tempo um lugar de vida e de trabalho, é hábitat (agri-cultura), é a casa, o lugar de viver, de criar hábitos. Trata-se do lugar da família, centrado em torno do patrimônio familiar, elemento de referência e de convergência, ao qual existe um sentimento de pertencimento, repleto de significações materiais e simbólicas que conformam suas heranças camponesas (WANDERLEY, 2000b; SILVA, 2005; 2009a).

A convergência entre espaço vivido e espaço explorado gera envolvimento com os ecossistemas do bioma e facilita práticas sustentáveis, pois para a maioria dos agricultores familiares do Cerrado a sua sobrevivência e a do bioma são uma só. A forma como eles utilizam os recursos naturais é diferenciada também pela presença do patrimônio cultural e pela lógica camponesa que eles são herdeiros. Isto faz com que eles detenham valores e estratégias específicos, frutos da coevolução do sistema social com o sistema natural e do longo e constante processo de convivência/aprendizado/adaptação com os ecossistemas naturais. Assim, ao contrário de erradicar a biodiversidade, os agricultores familiares exploram os recursos naturais de forma ambientalmente mais racional, em geral, respeitando a dinâmica ecológica, valorizando e preservando o bioma (SILVA, 2005; 2009a).

Conforme relata Silva (2009a; 2009b), os agricultores familiares habitantes do Cerrado aprenderam, de forma mais ou menos intensa, a basear seus modos de vida no extrativismo, caça, pesca e em estratégias agropecuárias que otimizam potencialidades do ambiente de transformar energia solar em alimentos, carnes e fibras. Aprenderam a utilizar as paisagens heterogêneas do bioma de forma igualmente heterogênea e diversificada; agricultura nas áreas de encosta e fundo de vale; solta de gado e extrativismo na chapada; sistemas que articulam caça, extrativismo e manejo do gado nas áreas alagadas. Desenvolveram enfim, um fluxo produtivo e de sustentação econômica que se ancorava no próprio fluxo temporal-espacial-ecológico da natureza e que se sustenta na combinação entre a pequena produção agropecuária e coleta de recursos vegetais nativos (SILVA, 2005; 2009a).

O protagonismo dos agricultores familiares para o desenvolvimento rural no Cerrado é, pois, fundamental. O reconhecimento e a valorização destes povos e de seus modos de vida são, não apenas indispensáveis, mas também urgentes, visto que são justamente neles que residem as bases para consolidação e difusão de outras formas de ocupação do Cerrado mais compatíveis com 
os aspectos de equidade e justiça social. Dentre estas, este artigo analisa na seção seguinte os modos de vida das famílias agroextrativistas.

\section{Agroextrativismo no Cerrado}

O extrativismo é, no sentido mais básico, uma maneira de produzir bens na qual os recursos naturais úteis são retirados diretamente da sua área de ocorrência natural, em contraste com a agricultura, o pastoreio, o comércio, o artesanato, os serviços ou a indústria. Esta diferença se dá pelo fato de que, no extrativismo, os produtos podem ser coletados, recolhidos, extraídos ou capturados sem necessidade de tratos anteriores, pois foram espontaneamente gerados e, em seus ciclos biológicos, não houve intervenção humana (DRUMMOND, 1996; HIRONAKA, 2000). Apesar de se referir tanto aos recursos de origem mineral, vegetal ou animal, para fins deste trabalho, o termo extrativismo é utilizado para designar, principalmente, o extrativismo vegetal, entendido como coleta ou apanha racional dos recursos florestais nativos como frutos, folhas, flores, sementes e madeiras.

O extrativismo faz parte da história social e cultural das comunidades rurais ao longo dos anos. Entretanto, a atividade é mais comumente associada apenas à Região Norte e à Floresta Amazônica. A própria bibliografia, conforme destaca Sawyer (2000), trata principalmente das regiões costeiro-marinha e amazônica. Publicações relacionadas ao extrativismo no Cerrado são recentes e pontuais, e sobre o semiárido são praticamente inexistentes. Porém, ainda hoje, o extrativismo constitui uma prática recorrente em todas as regiões do país e continua sendo realizado, de forma mais ou menos expressiva, por várias comunidades rurais. Menciona-se, por exemplo, o extrativismo do babaçu (Orbygnia martiana) nas regiões Norte e Nordeste e da carnaúba (Opernícia cerifera) no Nordeste, e ainda em várias outras regiões onde são extraídos frutos, plantas medicinais e ornamentais, flores ou frutos silvestres, permanecendo inclusive a pesca artesanal (RUEDA, 1995).

A coleta dos recursos vegetais nas áreas de ocorrência do bioma Cerrado, conforme afirma Sawyer (2000), não se trata de uma forma de reprodução e produção exclusivamente extrativista e totalmente especializada, como era o caso, por exemplo, do seringueiro clássico da Amazônia. Ao contrário, o extrativismo realizado pelos agricultores familiares habitantes dos ecossistemas de Cerrado constitui mais uma atividade, entre tantas outras, desempenhada pelas famílias em 
busca de melhores condições de vida e que está inserido em sistemas de produção familiares complexos, caracterizados pela combinação entre esta atividade e cultivos agrícolas diversificados.

Neste sentido, o termo que se faz mais adequado é o agroextrativismo. Vocábulo que procura retratar justamente a integração que os agricultores familiares sustentam com o extrativismo de recursos da biodiversidade, com atividades de produção agrícola e com a criação de gado e pequenos animais. Trata-se de uma ampliação do espectro sobre as atividades extrativistas que expressa as especificidades desse sistema de produção típico da agricultura familiar (NOGUEIRA; FLEISCHER, 2005).

Mais um aspecto distintivo do extrativismo no Cerrado diz respeito ao papel que a prática extrativa desempenha nos modos de vida das famílias. Esta por remeter à trajetória histórica dessas comunidades é repleta de representações simbólicas e valor cultural, o que não permite que sua importância e/ou viabilidade seja avaliada/entendida apenas do ponto de vista econômico. Isto porque a extração dos produtos vegetais, além de fazer parte da história de vida destas comunidades, é realizada não apenas para a comercialização nos mercados (valor comercial), mas também para trocas entre as famílias (trocas não mercantis) e para garantir e diversificar sua alimentação (autoconsumo).

No Assentamento Vale da Esperança, o agroextrativismo é caracterizado pela coleta de frutos nativos do Cerrado, baru (Dypterix alata), cagaita (Eugenia dysenterica), cajuzinho-docerrado (Anacardium humile), jatobá-do-cerrado (Hymenaea stigonocarpa), mangaba (Hancornia speciosa) e pequi (Caryocar brasiliense). A agricultura é basicamente o cultivo de milho, feijão, mandioca, arroz e cana-de-açúcar, além da criação de galinhas e gados de leite (MELO, 2013).

Da cesta de frutos extraídos no Projeto de Assentamento Vale da Esperança, o baru é o principal fruto coletado com finalidade comercial, sendo que os demais se destinam basicamente à alimentação doméstica. Esta estratégia de destinar parte da produção agroextrativista para autoconsumo resulta também na satisfação das necessidades básicas da família. Ao consumir sua própria produção, a família deixa de mobilizar recursos no mercado, poupando um montante financeiro que pode ser aplicado na compra de outros bens necessários à reprodução social ou para dar continuidade às próprias atividades agrícolas. Tal opção, na visão de Grisa et al. (2010), é fundamental, pois, além da economia de recursos financeiros, otimiza o uso de outros recursos disponíveis (principalmente terra e mão de obra) e permite que as famílias sofram menos com os efeitos da sazonalidade de rendas e das instabilidades climáticas. 
No Projeto de Assentamento Vale da Esperança, a possibilidade de elevação dos rendimentos constituiu a principal motivação para o início do extrativismo e comercialização do baru. As famílias relataram que a produção agropecuária do assentamento é baixa e o que sobra para comercialização, em geral, é muito pouco, resultando em uma renda bastante reduzida. Do universo de pesquisa, três famílias indicaram a atividade como a principal fonte de renda, sendo que as demais a apontaram como uma espécie de aporte, de complemento, que garante uma renda mensal e oferece maior segurança financeira para a família (MELO, 2013).

Não obstante as difíceis situações de infraestrutura e de acesso aos serviços públicos elementares, quando solicitadas a comparar as condições de vida que tinham antes de praticar o extrativismo com a situação atual, a maioria das famílias revelou que a situação atual é melhor do que a anterior. As que afirmaram não ter havido mudanças, justificam dizendo que precisam de muitas coisas e que gostariam de fazer mais com o a receita advinda do extrativismo (MELO, 2013).

No tocante aos aspectos ambientais, observou-se que as famílias agroextrativistas do Vale da Esperança estão vivenciando uma mudança de perspectiva e construção histórica, onde o Cerrado deixa de ser visto como vegetação que deveria ser eliminada para a execução de outras atividades e passa a ser valorizado não apenas por ser capaz de gerar renda, mas também como algo de grande relevância para o bem-estar da sociedade, transformação motivada fortemente pelo extrativismo. Embora a comunidade não pertença originalmente à localidade e não tenha vivido o mesmo processo de interação histórica com as paisagens do Cerrado como o que viveram e ainda vivem, por exemplo, as comunidades Geraizeiras de Minas Gerais pesquisadas por Silva (2009a), à medida que aumenta o envolvimento das famílias com a atividade de coleta dos frutos nativos, cresce também a preocupação com a necessidade de mudança de velhos hábitos para atitudes ambientalmente mais racionais e conscientes (MELO, 2013).

A leitura dos dados de pesquisa demonstrou que o extrativismo realizado pelas famílias e combinado com outras atividades produtivas (como agricultura em cultivos diversificados e a pequena criação de animais) representa uma atividade estratégica para a conservação do Cerrado, sendo capaz de contribuir com a melhoria das condições de vida nos espaços rurais do bioma. Os resultados indicaram que a atividade favorece o aumento e diversificação das fontes de renda, atua na geração de emprego e tem potencial para dinamizar a economia local.

O agroextrativismo representa uma outra possibilidade de utilização do território e do bioma Cerrado que contrasta com as prerrogativas do modo industrial e produtivista de fazer 
agricultura. Ao invés de substituir a vegetação nativa por monocultivos que simplificam os ecossistemas, a atividade depende da manutenção da vegetação e da biodiversidade. Características que acrescidas dos modos de vida específicos dos agricultores familiares, como racionalidade não estritamente mercantil, autossuficiência e autonomia, conhecimento integrado e não-fragmentado, trabalho e gestão familiar e potencialização dos recursos internos e locais provocam modificações no ambiente natural em escala menor do que a maioria das outras formas de uso da terra, permitindo que o Cerrado continue a apresentar sistemas ecológicos complexos, alta produtividade biológica e rica biodiversidade.

No que concerne à dimensão social, as constatações da pesquisa apontaram que o agroextrativismo favorece a segurança alimentar, pois facilita o acesso a uma multiplicidade de alimentos (frutos) saudáveis, naturais, sem aditivos químicos, de alto valor nutritivo e que, quase sempre, fazem parte dos hábitos alimentares das famílias que habitam o Cerrado. Fortalece também estratégias de autoconsumo, típicas dessas comunidades, permitindo a economia de recursos financeiros que podem ser aplicados na compra de outros recursos, necessários à reprodução social ou para dar continuidade a outras atividades produtivas. A prática da atividade auxilia ainda na manutenção do patrimônio cultural sobre o uso do Cerrado (encontra-se há muito tempo incorporada às estratégias cotidianas de sobrevivência das famílias que habitam seus ecossistemas) e facilita a permanência da agricultura familiar nos espaços rurais do bioma, onde eles estão habituados a morar e onde eles gostam de viver.

Apesar das potencialidades, o extrativismo ainda se depara com uma série de desafios. Alguns obstáculos são inerentes à atividade extrativista, como as dificuldades de controle e programação da produção, variação na quantidade de frutos produzida e dispersão geográfica das frutíferas. Outros estão mais relacionados à utilização comercial, como pouco conhecimento do mercado consumidor sobre o teor nutritivo e valor social dos produtos do Cerrado; necessidade de se estabelecer um preço justo que remunere além do esforço físico, a forma de produção diferenciada e os serviços prestados ao meio ambiente; dificuldades e custos elevados com transporte. Há também desafios como necessidade de organização e estruturação da atividade para interação satisfatória com os mercados e carência de ações públicas de fomento e apoio ao agroextrativismo.

No Vale da Esperança, as famílias entrevistadas consideram que os principais impedimentos referem-se à dificuldade de programar a produção e à instabilidade na quantidade de frutos produzidos (MELO, 2013). Situação recorrente, já que não é possível controlar os ciclos 
biológicos das frutíferas, tampouco prever a produção, e que no caso específico do baru, torna-se ainda mais complexa, pois trata-se de uma espécie que possui safras intermitentes, com variações bruscas na intensidade (quantidade) da produção.

Apesar das dificuldades, o universo pesquisado se mostrou otimista em relação às potencialidades do agroextrativismo. Os dados de campo indicaram que, independentemente da finalidade da coleta, quando perguntadas se havia vantagens em realizar o extrativismo, a afirmação positiva foi consenso. Entre as razões mencionadas com maior frequência, estão as contribuições para a preservação ambiental e reconhecimento da riqueza ecológica do Cerrado; a valorização do assentamento e da produção local; o aumento da renda e a diversificação da alimentação familiar (MELO, 2013).

A mitigação de algumas dessas dificuldades inclui iniciativas de cooperação, maior organização e dedicação dispensadas à atividade, e ainda o fortalecimento da identidade dos agricultores familiares do Cerrado e da internalização, nas famílias e na população como um todo, da importância da manutenção dos modos de vida diferenciados da lógica produtivista de ocupação que atualmente impera no bioma (MELO, 2013). Fomentar e valorizar o agroextrativismo constitui, portanto, uma estratégia de desenvolvimento rural. Mas, faz-se imprescindível que o Cerrado deixe de ser visto como fronteira, cuja utilidade central é a produção de commodities, e passe a ser valorizado pela riqueza que possui e pela diversidade dos ecossistemas nele existente.

\section{Conclusões}

Quando se trata de desenvolvimento rural, faz-se imprescindível evitar os reducionismos e a fragmentação excessiva da realidade. Deve existir sempre espaço para a incerteza, a emergência, a recursividade, a retroação, a auto-organização. É preciso considerar que conscientemente ou não algo sempre escapa e que a condição humana é limitada, não conseguindo englobar a totalidade dos fenômenos. Reflexões que apontam a inviabilidade de se pensar o meio rural com base em um único modelo, uma única forma de produção, um único modo de vida.

As novas abordagens do desenvolvimento rural ampliam o modo de enxergar, analisar e atuar no espaço rural, convidando para o reconhecimento das distintas possibilidades, modos de vida e formas de ocupação viáveis e existentes neste espaço que possui a diversidade como uma 
de suas características fundamentais. O Cerrado rural se mostra um lugar específico de vida e de trabalho, historicamente pouco conhecido e reconhecido pela sociedade brasileira, mas carregado de um grande potencial econômico, social, cultural e patrimonial. Nele coexiste uma variedade de ecossistemas, populações, culturas, sistemas produtivos, formas de organização social e política.

Ao contrário do que preconiza o projeto dominante de desenvolvimento, outras formas além daquela pautada na grande produção monocultora existem e não constituem em obstáculo ao desenvolvimento. Este trabalho abordou tais potencialidades a partir da experiência do agroextrativismo praticado pelos agricultores familiares residentes em um assentamento de reforma agrária do Estado de Goiás. A pesquisa apontou o agroextrativismo como uma atividade estratégica para a conservação do bioma, para a geração de renda das comunidades que o realizam, e com possibilidade de melhorar as condições de vida e, contribuir para a permanência dos agricultores no campo.

Entretanto, a despeito da relevância dos agricultores familiares e da viabilidade de atividades como o agroextrativismo, observa-se que as ações governamentais e políticas públicas direcionadas a estes atores e que contemplem suas especificidades ainda são escassas e pontuais. É imperioso, portanto, implementar medidas efetivas de apoio e estímulo a agricultura familiar e a formas diversificadas de produção e reprodução social no Cerrado. Estas devem ser atreladas a outras iniciativas territoriais de melhoria das condições de vida, aumento de renda e sustentabilidade ambiental, respeitando os modos de vida das comunidades que têm no bioma espaço de vida e trabalho.

Por fim, destaca-se a necessidade de se repensar as ações e políticas direcionadas ao espaço rural do Cerrado de modo a ampliar os objetivos do desenvolvimento para abranger não apenas crescimento econômico, mas também aspectos de cunho social que promovam mudanças positivas nas vidas das comunidades rurais, como redução das desigualdades, mitigação da pobreza e criação de bem-estar social.

\section{Referências}

ABRAMOVAY, R. Moratória para os cerrados: elementos para uma estratégia de agricultura sustentável. São Paulo: Departamento de Economia e Programa de Ciência Ambiental da USP, 1999.

. Muito além da economia verde. São Paulo: abril, 2012. 
BRASIL. Ministério do Meio Ambiente. Áreas prioritárias para conservação, uso sustentável e repartição de benefícios da biodiversidade brasileira: Atualização - Portaria MMA $n^{\circ}$ 9, de 23 de janeiro de 2007. Brasília: Ministério do Meio Ambiente, 2007.

. Monitoramento do desmatamento nos biomas brasileiros por satélite. Monitoramento do bioma Cerrado 2009 - 2010. Brasília: Ministério do Meio Ambiente, 2011.

DELGADO, N.G. O papel do rural no desenvolvimento nacional: da modernização conservadora dos anos 1970 ao Governo Lula. In: Ministério do Desenvolvimento Agrário. Brasil rural em debate. Brasília: MDA, CONDRAF, 2010. p. 28-78.

DIAS, B.F. de S. Cerrados: uma caracterização. In: DIAS, B. F. de S (coord.). Alternativas de desenvolvimento dos cerrados: Manejo e conservação dos recursos naturais renováveis. Brasília: Fundação Pró-Natureza, 1996. p. 11 a 25.

DRUMMOND, J.A. A extração sustentável de produtos florestais na Amazônia brasileira: vantagens, obstáculos e perspectivas. Estudos Sociedade e Agricultura. v.6, jul.1996. p. 115137.

GRISA, C.; GAZOLLA, M.; SCHNEIDER, S. A “produção invisível” na agricultura familiar: autoconsumo, segurança alimentar e políticas públicas de desenvolvimento rural. Agroalimentaria. v. 16, n. 31, jul. 2010. p. 65-79.

HIRONAKA, G.M.F.N. O extrativismo como atividade agrária. Jus Navigandi. Teresina: 2000.

KLINK, C.A.; MACHADO, R.B. A conservação do Cerrado brasileiro. Megadiversidade. v.1, n. 1, jul. 2005, p. 147-155.

MELO, S.W.C. Extrativismo vegetal como estratégia de desenvolvimento rural no Cerrado. jul 2013. Dissertação (Mestrado em Agronegócios) - Faculdade de Agronomia e Veterinária, Universidade de Brasília, Brasília 2013.

MORAES, R.C.; ÁRABE, C.H.G.; SILVA, M.P. Desenvolvimento e viés antiagrário. In: MORAES, R.C.; ÁRABE, C.H.G.; SILVA, M.P. As cidades cercam os campos. São Paulo: UNESP, 2008. p. 17-22.

MYERS, N.; MITTERMEIER, R.A.; MITTERMEIER, C.G.; FONSECA, G.A.B da.; KENT, J. Biodiversity hotspots for conservation priorities. Nature. v.403, feb. 2000.

NAVARRO, Z. Desenvolvimento rural no Brasil: os limites do passado e os caminhos do futuro. Estudos Avançados, v.15, n. 43, set./dez. 2001.

NOGUEIRA, M.; FLEISCHER, S. Entre tradição e modernidade: potenciais e contradições da cadeia produtiva agroextrativista no Cerrado. Estudos Sociedade e Agricultura, Rio de Janeiro, v.13, n.1, 2005. p. 125-157. 
RUEDA, R.P. Evolução histórica do extrativismo. In: MURRIETA, J.R.; RUEDA, R.P (Eds.). Reservas Extrativistas. Brasília: CNPT/Ibama, 1995.

SAUER, S. Agricultura familiar versus agronegócio: a dinâmica sociopolítica do campo brasileiro. Texto para Discussão, n. 30. Brasília: Embrapa Informação e Tecnológica, 2008.

SAWYER, D. População, meio ambiente e desenvolvimento sustentável no Cerrado. Brasília: Instituto Sociedade População e Natureza, 2000.

SAWYER, D.; LOBO, A. O papel da sociedade no estabelecimento de políticas públicas paras as savanas. In: FALEIRO, F.G.; FARIAS NETO, A.L. (Coords.) Savanas: desafios e estratégias para o equilíbrio entre sociedade, agronegócio e recursos naturais. Planaltina: Embrapa Cerrados, 2008. p. 1153-1181.

SCHNEIDER, S. Situando o desenvolvimento rural no Brasil: o contexto e as questões em debate. Revista de Economia Política, v. 30, n.3, p. 511-531, jul-set/2010.

SILVA, C.E.M. Lugar-hábitat e lugar-mercadoria: territorialidades em tensão nos domínios dos cerrados. In: ZHOURI, A.; LASCHEFSKI, K.; PEREIRA, D.B. (Orgs.). A insustentável leveza da política ambiental: desenvolvimento e conflitos socioambientais. Belo Horizonte: Autêntica, 2005. p. 217-244.

O Cerrado em disputa: apropriação global e resistências locais. Brasília: Confea, 2009a.

. Ordenamento Territorial no Cerrado brasileiro: da fronteira monocultora a modelos baseados na sociobiodiversidade. Desenvolvimento e Meio Ambiente. n.19, jan./jun. 2009b. p. 89-109.

WANDERLEY, M.N.B. Raízes históricas do campesinato brasileiro. In: XX Encontro Anual da ANPOCS, Caxambu, out. 1996.

. A emergência de uma nova ruralidade nas sociedades modernas avançadas - o "rural" como espaço singular e ator coletivo. Estudos Sociedade e Agricultura, Pernambuco, 2000a.

. A valorização da agricultura familiar e a reivindicação da ruralidade no Brasil.

Desenvolvimento e Meio Ambiente, n. 2, jul./dez. 2000b. p. 29-37.

Artigo recebido em 30/03/2017. Aceito para publicação em 29/05/2017. 